\title{
Target-Specific Properties of Thalamocortical Synapses onto Layer 4 of Mouse Primary Visual Cortex
}

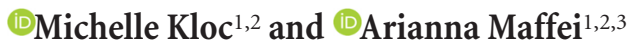 \\ ${ }^{1}$ Department of Neurobiology and Behavior, and ${ }^{2}$ Program in Neuroscience, SUNY-Stony Brook, Stony Brook, New York 11794, and ${ }^{3}$ SUNY Eye Research \\ Consortium
}

\begin{abstract}
In primary sensory cortices, thalamocortical (TC) inputs can directly activate excitatory and inhibitory neurons. In vivo experiments in the main input layer (L4) of primary visual cortex (V1) have shown that excitatory and inhibitory neurons have different tuning properties. The different functional properties may arise from distinct intrinsic properties of L4 neurons, but could also depend on cell type-specific properties of the synaptic inputs from the lateral geniculate nucleus of the thalamus (LGN) onto L4 neurons. While anatomical studies identified LGN inputs onto both excitatory and inhibitory neurons in V1, their synaptic properties have not been investigated. Here we used an optogenetic approach to selectively activate LGN terminal fields in acute coronal slices containing V1, and recorded monosynaptic currents from excitatory and inhibitory neurons in L4. LGN afferents made monosynaptic connections with pyramidal (Pyr) and fast-spiking (FS) neurons. TC EPSCs on FS neurons were larger and showed steeper short-term depression in response to repetitive stimulation than those on Pyr neurons. LGN inputs onto Pyr and FS neurons also differed in postsynaptic receptor composition and organization of presynaptic release sites. Together, our results demonstrate that LGN input onto L4 neurons in mouse V1 have target-specific presynaptic and postsynaptic properties. Distinct mechanisms of activation of feedforward excitatory and inhibitory neurons in the main input layer of V1 are likely to endow neurons with different response properties to incoming visual stimuli.
\end{abstract}

Key words: LGN; microcircuitry; optogenetics; synapses; thalamocortical; visual cortex

\section{Introduction}

The responsiveness of cortical circuits to sensory stimuli depends on the dynamics of activation of different neuron types. Excitatory and inhibitory neurons differ in their tuning to stimulus features and interocular bias. These differences are particularly marked in layer 4 (L4), the layer that receives the strongest thalamocortical (TC) projection (Cardin et al., 2007; da Costa and Martin, 2011). When compared with pyramidal (Pyr) neurons, inhibitory neurons are generally more broadly tuned to stimulus orientation (Niell and Stryker, 2008; Kuhlman et al., 2011; Zariwala et al., 2011; Atallah et al., 2012; Li et al., 2012; Cottam et al., 2013; Runyan and Sur, 2013), fire at higher frequencies in response to moving grating stimuli (Zhuang et al., 2013), and show less interocular bias (Yazaki-Sugiyama et al., 2009; Kameyama et al., 2010). The mechanisms regulating these differences are incompletely understood. Biophysical properties and firing patterns of excitatory and inhibitory neurons may partly explain their distinct responsiveness (Agmon and Connors, 1992; Contreras and Palmer, 2003). In addition, some of

\footnotetext{
Received June 25, 2014; revised 0ct. 3, 2014; accepted 0ct. 7, 2014.

Author contributions: M.K. and A.M. designed research; M.K. performed research; M.K. analyzed data; M.K. and A.M. wrote the paper.

This research was supported by a grant from The Whitehall Foundation to A.M. We thank Dr. Shaoyu Ge for help with the adeno-associated virus 9 construct; and Dr. Alfredo Fontanini, Dr. Yury Garkun, Dr. Trevor Griffen (SUNYStony Brook), and Dr. Jose-Manuel Alonso (SUNY-Department of Optometry) for useful comments and discussions.

Correspondence should be addressed to Arianna Maffei, Department of Neurobiology and Behavior, Life Science Building, Room 548, SUNY-Stony Brook, Stony Brook, NY 11794. E-mail: Arianna.maffei@stonybrook.edu.

DOI:10.1523/JNEUROSCI.2595-14.2014

Copyright $\odot 2014$ the authors $\quad 0270-6474 / 14 / 3415455-11 \$ 15.00 / 0$
}

these differences could be shaped by TC inputs if they showed target-specific properties, as in other sensory cortical circuits.

Recordings in vivo strongly suggest that excitatory and fastspiking (FS) neurons are directly activated by incoming visual inputs (Contreras and Palmer, 2003; Cardin et al., 2007), from retinotopically aligned neurons in the dorsolateral geniculate nucleus of the thalamus (dLGN; Zhuang et al., 2013). Inputs from the dLGN are thought to activate a small number of powerful inputs on L4 neurons (Freund et al., 1985; Stratford et al., 1996). The presynaptic and postsynaptic properties of dLGN inputs on excitatory and inhibitory neurons in L4 of visual cortex (V1) have not been investigated; thus, it is currently unknown whether the distinct response properties of this neuronal population could be due, at least in part, to target-specific dynamics of activation.

Here we confirm that LGN afferents make direct synaptic contacts with excitatory Pyr and FS neurons in L4 of mouse V1. Consistent with previous studies in the primary somatosensory cortex (S1; Cruikshank et al., 2007) and in the primary auditory cortex (A1; Viaene et al., 2011; Schiff and Reyes, 2012), LGN inputs in both Pyr and FS neurons can be classified as type I (or drivers; Sherman, 2007, 2012), as their activation evokes large currents showing short-term depression to repetitive stimulation. LGN inputs in distinct neuron types differ significantly in the number of presynaptic release sites, postsynaptic receptor composition, conductance, and number of postsynaptic channels contributing to the evoked response. Our data suggest that target-specific mechanisms of activation of LGN inputs contribute to the distinct dynamics of activation of excitatory and inhibitory neurons evoked by visual stimuli. 


\section{Materials and Methods}

Surgical procedures. The surgery and experimental procedures were approved by the Stony Brook University Animal Use Committee. Both male and female mice were included in the study. To selectively drive LGN terminal fields in $\mathrm{V} 1$, we introduced the light-gated conductance channelrhodopsin-2 (ChR2) in the LGN using the vector adenoassociated virus serotype 9 (AAV9; Gu et al., 2012; Wang et al., 2013). The construct was injected into the LGN of postnatal day 15 (P15) mice anesthetized with a cocktail of $100 \mathrm{mg} / \mathrm{kg}$ ketamine and $10 \mathrm{mg} / \mathrm{kg}$ xylazine using a Nanoject pressure injection system $\left(50 \times 10^{12}\right.$ viral particles/nl; Wang et al., 2013). The coordinates of injection were $2.0 \mathrm{~mm}$ posterior from bregma, $1.9 \mathrm{~mm}$ lateral from the midline, and $2.9 \mathrm{~mm}$ below the pia. This procedure resulted in the expression of ChR2-GFP localized in the LGN following a $10 \mathrm{~d}$ incubation period (Fig. 1A). The construct did not leak into the cortical area above the injection site, so there was no aspecific expression of the construct in the structures above the LGN. The subtype of AAV was chosen for its preferred anterograde transport. To further confirm the lack of retrograde transport, we quantified the possible presence of backfilled somata across the entire cortical mantle in each slice used for this study. None of the preparations showed backfilled somata in any layer of $\mathrm{V} 1$, similar to what we reported in our previous study (Wang et al., 2013). To assess the reliability of the levels of expression of the ChR2-GFP construct in the LGN and in LGN terminal fields in V1 across preparations, a group of animals was perfused transcardially with $4 \%$ paraformaldehyde in phosphate buffer $10 \mathrm{~d}$ after injection. Coronal slices containing either LGN (to verify the location of the injection site) or V1 $(100 \mu \mathrm{m})$ were visualized with confocal microscopy. The location, spread, and intensity of the GFP signal was quantified using ImageJ. In slices containing V1, the intensity profile of the GFP signal was quantified in regions of interest (ROIs) spanning the cortical mantle (ROI: $40 \mu \mathrm{m}$ wide and extending from the pial surface to the border between layer 6 and the white matter). A calibration curve of the levels of GFP fluorescence across layers was calculated as the average \pm SD of the GFP intensity measured in 15 slices from six animals (Fig. 1C, green line, average, black lines, \pm SD). The intensity of the GFP signal of all subsequent preparations was compared against this curve. Recordings were excluded from the analysis if obtained from slices in which the GFP signal deviated more than 1 SD from the calibration curve.

Recordings. Mice were deeply anesthetized by placing them in a closed jar saturated with isoflurane vapors. They were then decapitated, and the brain was dissected out to prepare acute coronal slices containing LGN or V1 $10 \mathrm{~d}$ after injection of the AAV9-ChoP2-GFP construct (Wang et al., 2013). For each preparation, the location of the injection site was visually identified on the day of the experiment and histologically verified post $h o c$. The functional expression of the construct was assessed by preparing acute LGN slices and recording from LGN neurons. Brief $(2 \mathrm{~ms})$ light stimuli $(470 \mathrm{~nm})$ were delivered through a $40 \times$ water-immersion objective of an upright microscope (BX51WI, Olympus) positioned directly
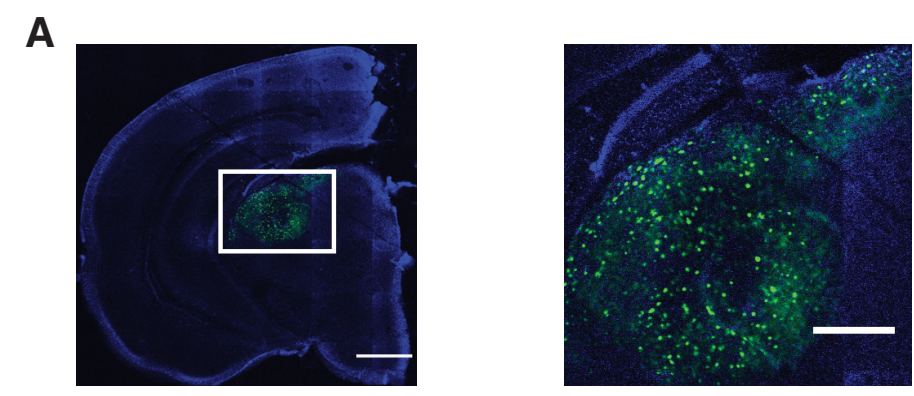

B

$5 \mathrm{~Hz}, 0.3 \mathrm{~mW} / \mathrm{mm}^{2}$

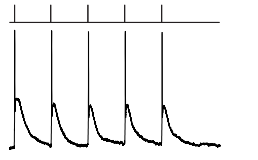

$10 \mathrm{~Hz}, 0.3 \mathrm{~mW} / \mathrm{mm}^{2}$

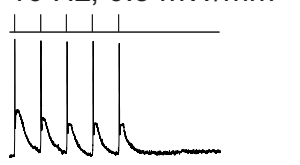

$20 \mathrm{~Hz}, 0.3 \mathrm{~mW} / \mathrm{mm}^{2}$

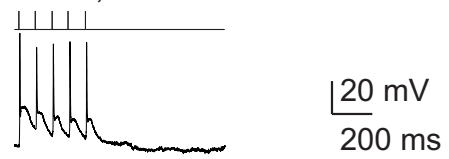

C
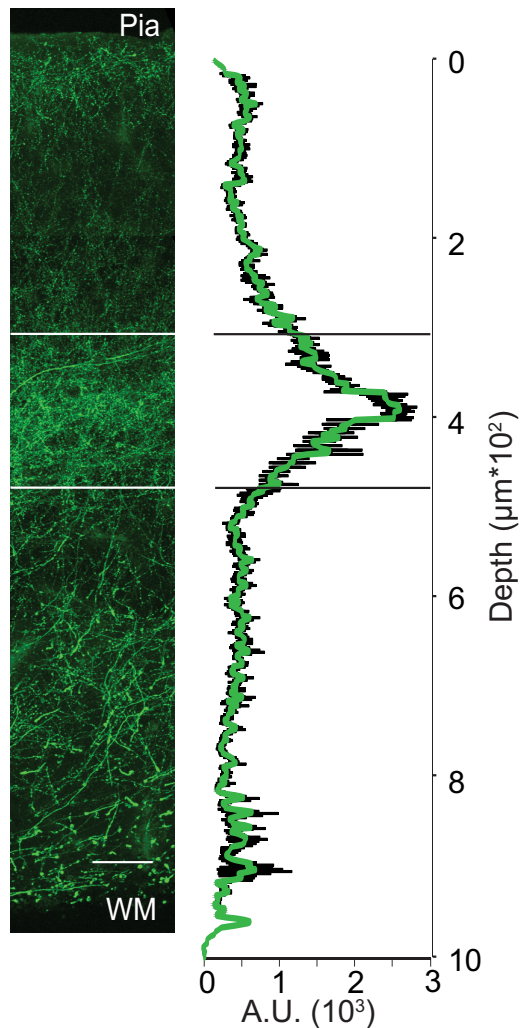

Figure 1. Expression of ChR2-GFP in LGN and V1.A, Left, Representative histology of a section showing expression of ChR2-GFP at P27 (injection at P15). Green, ChR2-GFP; blue, DAPI. Scale bar, $1 \mathrm{~mm}$. Right, Enlarged image of the region indicated by the white square in the image on the left. Scale bar, $40 \mu \mathrm{m}$. $\boldsymbol{B}$, Top, Slice of LGN expressing ChR2-GFP and containing a recorded neuron (indicated by the arrowhead). The somatic expression of the injected construct (green) is colocalized with the biocytin staining (red), thus the recorded neuron appears yellow. Scale bar, $40 \mu \mathrm{m}$. Bottom, Light-evoked action potentials in the LGN neuron shown in the top image. Light stimulus intensity, $0.3 \mathrm{~mW} / \mathrm{mm}^{2}$. Trains of light pulses at 5,10 , and $20 \mathrm{~Hz}$ were delivered while the neuron was recorded in the presence of AMPA and NMDA receptor blockers to ensure that the action potentials depended on the activation of the light-gated protein. C, Left, Expression of ChR2-GFP in the LGN terminal fields in V1. Right, Calibration curve of GFP intensity across the cortical mantle (see Materials and Methods). Green, Average GFP intensity across 15 slices from six animals; black traces, \pm 1 SD from the average fluorescence calculated across the 15 slices. Scale bar, $100 \mu \mathrm{m}$.

above the recording chamber, and their ability to reliably elicit action potentials in LGN neurons was determined. This procedure was performed at the beginning of each experiment. To further test that action potentials in LGN neurons were driven by light pulses and not by synaptic activity, the experiments were repeated in the presence of $20 \mu \mathrm{M} 6,7$-dinotroquinoxaline2,3(1H,4H)-dione (DNQX) and $50 \mu \mathrm{M} \mathrm{D}$-2-amino-5-phosphonovalerate (APV) to block AMPA receptors (AMPARs) and NMDA receptors (NMDARs; Fig. 1B).

After verification that the expression level of the construct in the LGN was sufficient to drive LGN neurons above the threshold for action potentials (Fig. 1B), recordings were performed in acute coronal slices containing V1, where light stimuli were used to selectively activate the LGN 
terminal fields. Different neuron types in L4 were visually identified under infrared microscopy. In these experiments, LGN terminal fields were driven with either one or multiple $2 \mathrm{~ms}$ pulses of $470 \mathrm{~nm}$ light. Light intensity was regulated through an epifluorescent light source (range of intensity at the tissue level, $0.1-0.3 \mathrm{~mW} / \mathrm{mm}^{2}$ ), and passed through a blue filter. Light stimulation was synchronized with electrophysiological recordings via the connection of a shutter (Sutter) to the analog output of a Multi-patch-clamp amplifier (HEKA). The power of the light stimuli in the recording chamber was quantified using an optical power meter (Coherent, Inc). Light-evoked synaptic responses were aligned off-line at $10-90 \%$ of rise time. Four simultaneous patch-clamp recordings were used to compare the properties of LGN-evoked responses in distinct neuron types within the same slice before quantifying population data across preparations.

Criteria to define responses as monosynaptic. TC EPSCs were considered monosynaptic if their delay from stimulus onset was $<2.5 \mathrm{~ms}$ and did not show any additional peak on the decay phase of the postsynaptic current. A group of Pyr (17\%) and FS (34\%) neurons showed disynaptic currents, which were detected as additional peaks on the decay phase of the evoked response. The delay from stimulus onset of those later peaks was on average $11.4 \pm 0.2 \mathrm{~ms}$. As the theoretical reversal potential in our internal solution is $-50 \mathrm{mV}$, even inhibitory disynaptic events are detectable as inward currents on the decay phase of the evoked TC EPSC. All recorded neurons showing disynaptic responses were excluded from the analysis; therefore, the number of samples reported in the manuscript selectively indicates neurons whose responses fit our definition of monosynaptic TC EPSC. Nonstationary peak-scaled noise analysis and analysis of release properties were performed on TC EPSCs evoked with minimal light intensity to activate putative single axons. While minimal light intensity evoked TC EPSCs with amplitudes comparable to those evoked by focal laser stimulation (Cruikshank et al., 2010) and those evoked by minimal electrical stimulation in thalamocortical slices in the somatosensory cortex (Beierlein et al., 2003) in both Pyr and FS neurons, in our preparations we did not observe failures. The absence of failures likely depends on the depolarization of terminals evoked by direct activation of the light-gated sodium conductance expressed by LGN axons.

Post hoc neuron identification. During recordings, neurons were filled with $0.4 \%$ biocytin. After completion of the recordings, slices were fixed in a $4 \%$ paraformaldahyde PBS solution for 1 week. Slices were then washed in PBS, permeabilized with $1 \%$ Triton X-100 in PBS for $2 \mathrm{~h}$, and incubated overnight at $4^{\circ} \mathrm{C}$ in a solution containing streptavidinconjugated AF-594 (1:1000, Invitrogen) and 0.1\% Triton X-100 in PBS. After this incubation period, slices were washed in PBS, mounted on glass slides with Fluoromount, and coverslipped. Slices were imaged with a fluorescent microscope (Axioskop, Zeiss). Only neurons located in L4 were used in the analysis.

Nonstationary noise analysis. Nonstationary noise analysis (Sigworth, 1980; Traynelis and Jaramillo, 1998; Hartveit and Veruki, 2007) was applied to determine the single-channel conductance and number of open channels of EPSCs (i.e., TC EPSCs). The analysis was performed on TC EPSCs recorded at $-70 \mathrm{mV}$ in the presence of the NMDA receptor blocker APV $(50 \mu \mathrm{M})$ to determine differences in the properties of the AMPA receptor-mediated component of the TC EPSC. For each neuron, 10 light-evoked TC EPSCs were averaged, and each individual trace was scaled to the mean. The variance of the TC EPSCs during the decay phase was averaged in $1 \mathrm{~ms}$ bins, and plotted against the mean current. This plot was fitted to a polynomial equation $\sigma^{2}=i I-\left(I^{2} / N\right)$ to calculate unitary current $\left(i_{u}\right)$ and the number of open channels $\left(N_{o}\right)$.

Analysis of release properties. Strontium chloride $\left(\mathrm{SrCl}_{2}\right)$ is known to produce delayed asynchronous release (Goda and Stevens, 1994) and has a long lifetime in the presynaptic terminal (Xu-Friedman and Regehr, 2000). Bath application of $\mathrm{SrCl}_{2}$ was shown to decrease the amplitude of an evoked response down to that driven by release at a single release site (Morishita and Alger, 1997; Bartley et al., 2008). The amplitude of a single release site-evoked response varies depending on the presynaptic cell (Daw et al., 2009). The remaining desynchronized release sites produce synaptic events that can be detected in the decay phase of the first evoked response (up to $200 \mathrm{~ms}$ from stimulus onset). In a set of experiments, $10 \mathrm{~mm} \mathrm{SrCl}_{2} / 0 \mathrm{mM} \mathrm{CaCl}_{2}$ was bath applied following the acquisi- tion of a 10 min baseline TC EPSC. The effect of $\mathrm{SrCl}_{2}$ on the amplitude of the evoked TC EPSC was quantified, and the number of subsequently activated release sites was inferred by assessing the number of events detected across the $200 \mathrm{~ms}$ time window from the light stimulus.

Quantal analysis. To assess the site of action of $\mathrm{SrCl}_{2}$, quantal analysis was performed on the first evoked response before and after application of $\mathrm{SrCl}_{2}$ (Sola et al., 2004; Wang et al., 2012). A binomial model (Wernig, 1975 ) was fit to the data to calculate the probability of release $(p)$ and the number of release sites $(n)$ from the average TC EPSC amplitude and coefficient of variation $(\mathrm{CV})$. Statistical comparisons of CVs before and after applications of $\mathrm{SrCl}_{2}$ were also provided for each neuron type.

Statistical analysis. All data are presented as the mean \pm SE. Statistical significance was determined using two-tailed unpaired Student's $t$ tests. Significant differences across groups were assessed with one-way ANOVAs. Spearman rank-order correlation analysis was applied to determine the possible correlations of the magnitude of the effect of $\mathrm{SrCl}_{2}$ on the first evoked TC EPSC with the baseline amplitude of the TC EPSC; $p$ values $\leq 0.05$ were considered to be significant.

Solutions. Artificial CSF (ACSF) contained the following (in mM): 126 $\mathrm{NaCl}, 3 \mathrm{KCl}, 2 \mathrm{MgSO}_{4}, 1 \mathrm{NaHPO}_{4}, 25 \mathrm{NaHCO}_{3}, 2 \mathrm{CaCl}_{2}$, and $14 \mathrm{dex}-$ trose. The internal solution contained the following (in mM): $20 \mathrm{KCl}, 100$ K-Glu, 10 K-HEPES, 4 Mg-ATP, $0.3 \mathrm{Na}$-GTP, $10 \mathrm{Na}$-phosphocreatine, and $0.4 \%$ biocytin. The $\mathrm{pH}$ of the internal solution was adjusted to 7.35 with $\mathrm{KOH}$, and the osmolarity was adjusted to $295 \mathrm{mOsm}$ with sucrose. In all pharmacological experiments, drugs were bath applied. In experiments designed to quantify the NMDA/AMPA ratio, $3 \mu \mathrm{M}$ QX-314 (Tocris Bioscience) was added to the internal solution. All other drugs were bath applied. For isolating AMPA and NMDA receptor-mediated components, $20 \mu \mathrm{M}$ DNQX (Tocris Bioscience) and $50 \mu \mathrm{M}$ APV (Tocris Bioscience) were applied sequentially and additively. To desynchronize release sites, $10 \mathrm{~mm} \mathrm{SrCl}_{2}$ (Sigma-Aldrich) was added to a $\mathrm{CaCl}_{2}$-free ACSF following acquisition of a $10 \mathrm{~min}$ baseline.

\section{Results \\ Selective activation of thalamocortical afferents in acute V1 slices}

Obtaining a reliable preparation for the detailed study of the synaptic properties of LGN inputs to V1 has proven difficult due to the complex anatomy of the LGN projection (MacLean et al., 2006). Thus, to selectively activate LGN inputs we used an optogenetic approach that allowed for the stimulation of LGN terminal fields in V1 (Wang et al., 2013). After a 10 d incubation period, LGN slices were prepared to assess the effectiveness of the expression of the ChR2-GFP construct. Whole-cell currentclamp recordings confirmed that LGN neurons expressed the construct and could be driven above the action potential threshold using brief light stimuli ( $2 \mathrm{~ms}, 0.3 \mathrm{~mW} / \mathrm{mm}^{2}$ ), even in the presence of AMPA and NMDA receptor blockers (Fig. $1 B)$. The ability of LGN neurons to fire action potentials following the frequency of stimulation was assessed experimentally. In the presence of AMPA and NMDA receptor blockers, LGN neurons fired action potentials reliably in response to trains of light pulses up to $20 \mathrm{~Hz}$ (Fig. $1 B$ ). This is consistent with the reported kinetics of activation and deactivation of ChR2 (Zhang et al., 2006).

Acute coronal slices containing V1 were also prepared to visualize and activate LGN terminal fields. To assess consistency of expression across preparations, a fluorescence intensity profile was measured across laminae and a calibration curve for the intensity of GFP fluorescence was obtained by averaging 15 slices from 6 animals that received the AAV9-ChR2-GFP injection in the LGN (Fig. 1C; see also Materials and Methods; Wang et al., 2013). GFP expression for all preparations was then compared against a calibration curve, and only data recorded from slices whose fluorescence profile fell within 1 SD of the mean calibration curve were included in the analysis. The possible presence of 
backfilled somata in every layer of V1was assessed for each preparation. No backfilled somata were observed in any layer, confirming that LGN afferents were the only light-sensitive component of V1 in our preparation.

LGN inputs have cell type-specific properties in layer 4 of $\mathrm{V} 1$

Anatomical evidence suggests that the LGN directly innervates both pyramidal and inhibitory neurons in L4 (Freund et al., 1985; Ahmed et al., 1994, 1997; Erisir and Dreusicke, 2005), but whether LGN inputs onto distinct neuron types differ in their synaptic properties has not been investigated. To address this, we recorded from Pyr neurons and two distinct populations of inhibitory neurons, and compared their synaptic responses to the activation of LGN terminal fields. Light activation of LGN axons elicited reliable TC EPSCs in every Pyr (Fig. $2 A, D$ ) and FS (Fig. $2 B, D$ ) neuron recorded. In a subset (three of six) of regular spiking nonpyramidal (RSNP) neurons, a small but reliable current was also detected (Fig. 2C,D). When the latency from stimulus onset of postsynaptic responses was quantified and compared across cell types, only responses from Pyr and FS neurons were consistent with monosynaptic inputs, while responses in the RSNP neurons were not (Fig. 2E; Pyr neurons: $1.62 \pm$ $0.05 \mathrm{~ms} ; n=29$; FS neurons: $1.34 \pm 0.1$ ms; $n=15$; RSNP neurons: $7.34 \pm 0.2 \mathrm{~ms}$; $n=6)$. The three distinct neuron types were often recorded simultaneously using quadruple patch clamp; thus, the differences observed are not due to artifacts of light stimulation or inconsistencies across preparations. Together, these results support the interpretation that Pyr and FS neurons receive strong and reliable LGN inputs with delay from stimulus compatible with monosynaptic connections, while RSNP neurons do not.

Because they receive reliable LGN inputs compatible with the presence of monosynaptic connections, we focused our analysis on the comparison of synaptic properties and dynamics of TC responses evoked in Pyr and FS neurons. TC EPSCs recorded from Pyr neurons had significantly slower rise and decay time constants than those recorded from FS neurons (rise time: Pyr neurons, $1.76 \pm$ $0.08 \mathrm{~ms}, n=29$; FS neurons, $0.9 \pm 0.09$ ms, $n=15$; unpaired $t$ test, $p<0.001$; decay time constant: Pyr neurons, $12.1 \pm 0.9 \mathrm{~ms}$; FS neurons, $6.4 \pm 0.4 \mathrm{~ms} ; p<0.001)$. Stimuli with increasing light intensity $\left(0.1-0.3 \mathrm{~mW} / \mathrm{mm}^{2}\right)$ were used to examine the input/output relationship of LGN inputs in Pyr and FS neurons. The amplitude

B

D
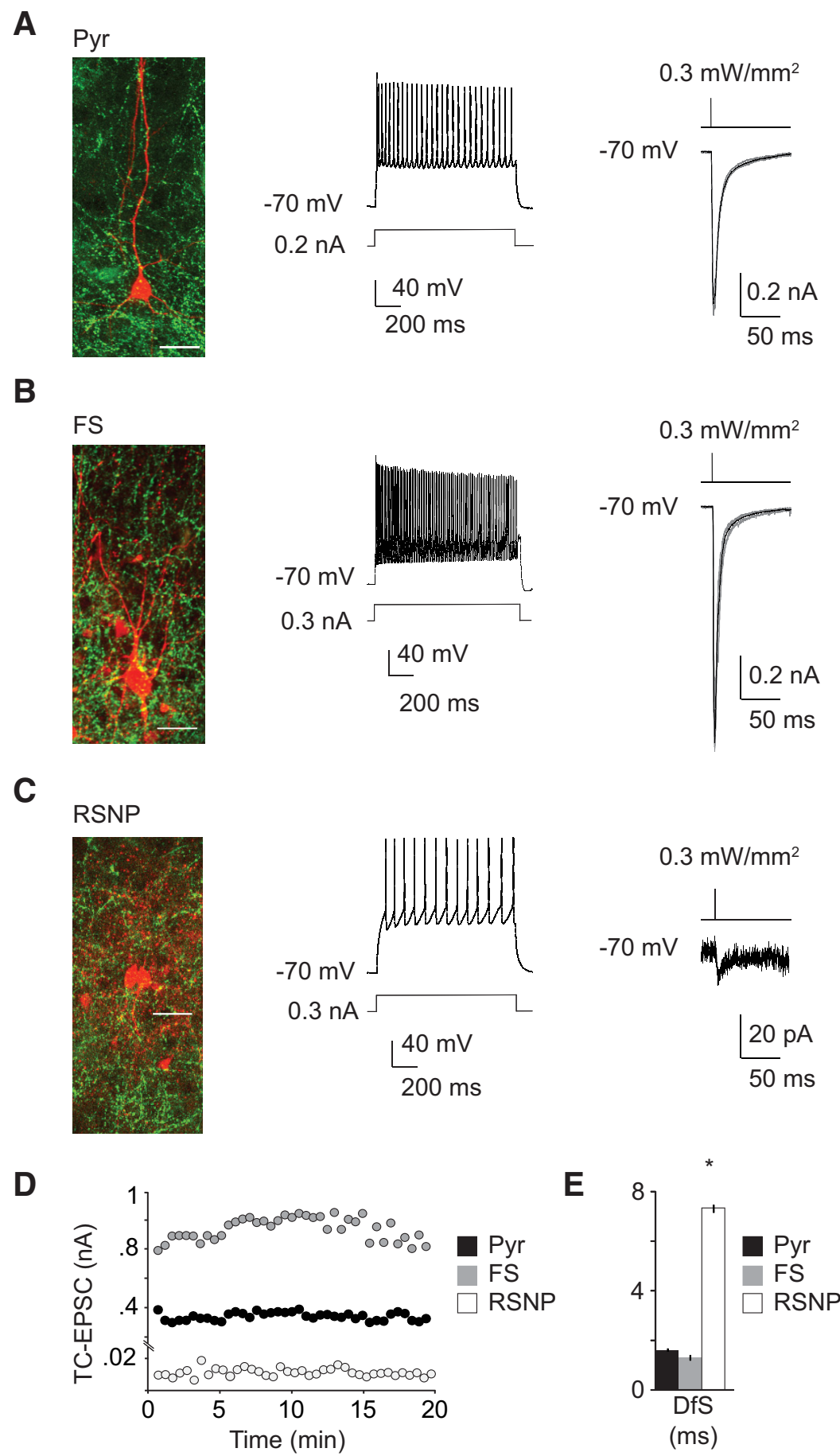

Figure 2. Monosynaptic inputs from the LGNinto Pyr and FS neurons. A, Left, Posthoc reconstruction of an L4 pyramidal neuron (green ChR2-GFP; red, biocytin-Alexa Fluor 594 as in B and C, left panels). Middle, Firing pattern of the Pyr neuron on the left in response to a $0.2 \mathrm{nA}$, 1s current step. Right, Light-evoked TC EPSCs recorded from the neuron shown in the left panel (light pulse: $2 \mathrm{~ms}, 0.3 \mathrm{~mW} / \mathrm{mm}^{2}$; same for the right panels in $\boldsymbol{B}$ and $\boldsymbol{C}$, and for $\boldsymbol{D}$ ). Gray, Single traces; black, average of 30 traces. $\boldsymbol{B}$, Left, FS neurons recorded in $\mathrm{L} 4$ of the V1. Middle, Firing pattern of the $\mathrm{FS}$ neuron on the left in response to $0.3 \mathrm{nA}, 1 \mathrm{~s}$ long current step. Right, Light-evoked TC EPSC recorded from the FS neuron on the left. Gray, Single traces; black, average of 30 traces. C, Left, Posthoc reconstruction of an RSNP neuron recorded in L4. Middle, Firing pattern of the L4RSNP shown on the left in response to a $0.2 \mathrm{nA}$ current pulse. Right, TCEPSC evoked by a brieflight pulse and recorded from the RSNP neuron on the left. Gray, Single traces; black, average of 30 traces. $D$, Time course of light-evoked TCEPSCs for neurons shown in $\boldsymbol{A}$ (black), $\boldsymbol{B}$ (gray), and $\boldsymbol{C}$ (white), indicating that responses were stable over time. $\boldsymbol{E}$, Average TC EPSC latency from stimulus onset for Pyr, $F S$, and RSNP neurons. Data are presented as the mean \pm SE. Asterisks indicate significant differences.

of TC EPSCs in FS neurons was significantly larger than those in Pyr neurons for all stimulus intensities except for the lowest (Fig. $3 A-C ; 0.1 \mathrm{~mW} / \mathrm{mm}^{2}$ : Pyr neurons, $160 \pm 39.3 \mathrm{pA}$; FS neurons, $236.4 \pm 132.7 ; p=0.07 ; 0.15 \mathrm{~mW} / \mathrm{mm}^{2}$ : Pyr neurons, $217.04 \pm$ 
A Pyr

B
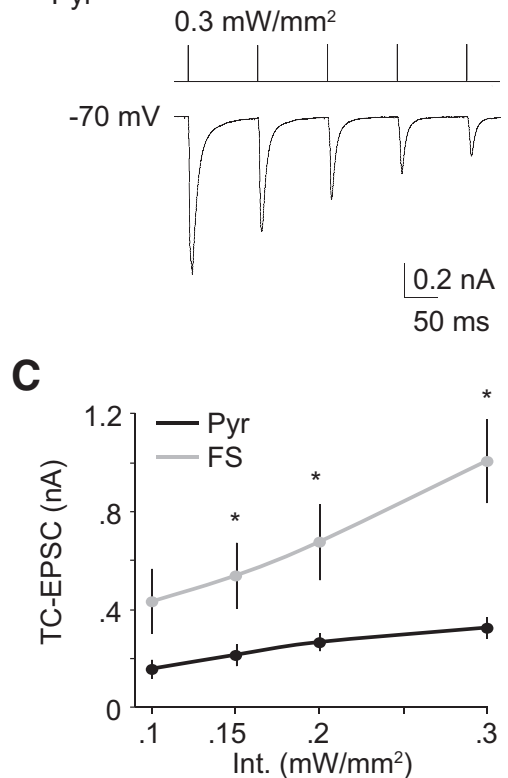

FS

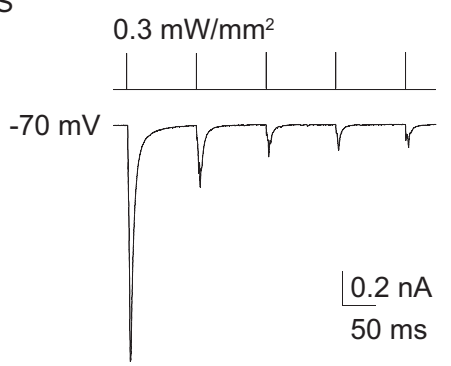

D

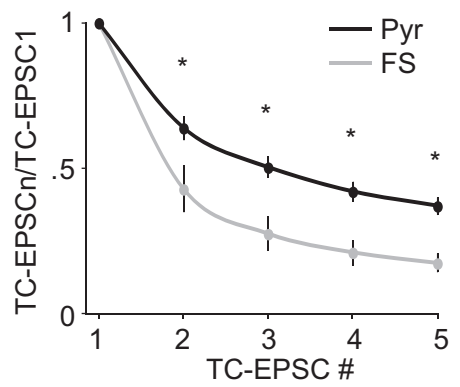

neurons were recorded in current clamp. Pyr and FS neurons showed detectable TC EPSPs at all stimulus intensities (Fig. $4 A, B)$. However, every recorded FS neuron fired at least one action potential at both the minimum and maximum light intensity (Fig. 4C, 14 of 14). Conversely, $23.8 \%$ (Fig. $4 C$ ) of Pyr neurons ( 15 of 63 neurons; Pearson $\chi^{2}$ test, $p<0.02$ ) fired an action potential at the lowest light intensity, and only 44\% (Fig. 4C; 28 of 63 neurons; Pearson $\chi^{2}$ test, $p<0.05$ ) fired at least one action potential at the highest light intensity. The ratio of action potentials per light stimulus was used to calculate a spike reliability ratio (i.e., the SRR). At all stimulus intensities, FS neurons fired significantly more action potentials per light stimulus than pyramidal neurons (Fig. $4 D$, SRR; $0.1 \mathrm{~mW} / \mathrm{mm}^{2}$ : Pyr neurons, $0.09 \pm 0.03$; FS neurons, $0.62 \pm$ 0.16 ; unpaired $t$ test, $p<0.03 ; 0.15 \mathrm{~mW} /$ $\mathrm{mm}^{2}$ : Pyr neurons, $0.1 \pm 0.03$; FS neurons, $1 \pm 0.001 ; p<0.001 ; 0.2 \mathrm{~mW} / \mathrm{mm}^{2}$ : Pyr neurons, $0.16 \pm 0.04$; FS neurons, $1.56 \pm 0.2 ; p<0.001 ; 0.3 \mathrm{~mW} / \mathrm{mm}^{2}:$ Pyr neurons, $0.3 \pm 0.05$; FS neurons, $1.7 \pm$ $0.2 ; p<0.001$; Pyr neurons, $n=63$; FS neurons, $n=14$ )

Figure 3. Distinct input- output curves and short-term dynamics of TC EPSCS in FS and Pyr neurons. $\boldsymbol{A}$, Sample TC EPSC recorded from $L 4$ Pyr neurons, in response to a train of five light pulses at $10 \mathrm{~Hz}$. Intensity of light pulses, $0.3 \mathrm{~mW} / \mathrm{mm}^{2}$. B, Sample TC EPSCs recorded from $L 4 \mathrm{FS}$ neurons in response to a train of five light pulses at $10 \mathrm{~Hz}$. Intensity of light pulses, $0.3 \mathrm{~mW} / \mathrm{mm}^{2}$.C Input- output curves for L4 Pyr (black) and FS (gray) nrurons. D, Normalized amplitude of TC EPSCs in the train for Pyr (black) and FS (gray) neurons. Data are presented as the mean \pm SE. Asterisks indicate significant differences.

42.9 pA; FS neurons, $541.9 \pm 134.8 \mathrm{pA} ; p<0.02 ; 0.2 \mathrm{~mW} / \mathrm{mm}^{2}$ : Pyr neurons, 269.1 $\pm 37.8 \mathrm{pA}$; FS neurons, $680.1 \pm 154.5 \mathrm{pA} ; p<$ 0.03; $0.3 \mathrm{~mW} / \mathrm{mm}^{2}$ : Pyr neurons, $328.3 \pm 41.9 \mathrm{pA}$; FS neurons, $1009.56 \pm 169.2 ; p<0.05$; Pyr neurons, $n=29$; FS neurons, $n=$ 15). Furthermore, the slope of the input-output curve was steeper for FS neurons than for Pyr neurons (Pyr neurons, 0.83 $\mathrm{nA} / \mathrm{mW}$; FS neurons, $2.91 \mathrm{nA} / \mathrm{mW} ; p<0.05)$. These results suggest that a single incoming stimulus would likely activate the feedforward inhibitory circuit more effectively than the excitatory circuit.

We next examined the short-term dynamics of TC EPSCs to assess how trains of stimuli may engage feedforward excitatory and inhibitory circuits. We chose to use a $10 \mathrm{~Hz}$ frequency of repetitive stimulation, because this frequency is reliably followed by the kinetics of activation and inactivation of ChR2 (Zhang et al., 2006; Gu et al., 2012; Wang et al., 2013), and is reliably followed by LGN neurons (Fig. 1B). In response to trains of five light pulses, we observed short-term depression of TC EPSCs of different magnitude depending on the postsynaptic target. TC EPSCs onto FS neurons showed a larger initial TC EPSC followed by much smaller subsequent events. Pyramidal neurons showed a less dramatic decrease in amplitude of successive TC EPSCs (Fig. 3D). These distinct short-term dynamics resulted in significantly different paired-pulse ratios (PPRs) and steady-state ratios (SSRs) between neuron types (PPRs: Pyr neurons, $0.66 \pm 0.04$; FS neurons, $0.56 \pm 0.05 ; p<0.01$; SSRs: Pyr neurons, $0.38 \pm 0.03$; FS neurons, $0.25 \pm 0.03$; $p<0.006$; Pyr neurons, $n=29$; FS neurons, $n=15$ ). Thus, LGN inputs in Pyr and FS neurons differ in both synaptic strength and short-term dynamics.

Before analyzing the specific synaptic mechanisms determining TC EPSC cell type-specific properties, we assessed how repetitive activation of TC terminal fields may affect the ability to fire action potentials in Pyr and FS neurons. To do that, Pyr and FS
The difference in the ability of LGN inputs to drive Pyr and FS neurons above threshold did not depend on differences in resting input resistance, as FS input resistance $\left(R_{i}\right)$ was lower than that of Pyr neurons ( $R_{i}$ : Pyr neurons, $192 \pm 10 \mathrm{M} \Omega$; FS neurons, $138 \pm$ $8 \mathrm{M} \Omega$; unpaired $t$ test, $p<0.02$ ). We hypothesized that the ability of Pyr neurons to fire action potentials in response to LGN terminal field activation may be shunted by feedforward inhibition. Consistent with this, partial blockade of $\mathrm{GABA}_{\mathrm{A}}$ receptors with bath application of picrotoxin $(10 \mu \mathrm{M})$ allowed all recorded Pyr neurons to fire action potentials in response to a single light pulse at $0.1 \mathrm{~mW} / \mathrm{mm}^{2}$ (Fig. $4 A$, gray overlay; 10 of $10 \mathrm{Pyr}$ ). These data indicate that TC afferents drive feedforward inhibition in V1 more effectively than feedforward excitation, and that feedforward inhibition acts as a brake on LGN activation of V1 pyramidal neurons.

\section{Cell type-specific postsynaptic differences of TC EPSCs in V1}

Our findings so far suggest that LGN inputs onto Pyr and FS neurons in L4 of the V1 show differences in kinetics, strength, and short-term dynamics. The differences in decay kinetics and average amplitude suggest that these inputs may be driving different receptor types on Pyr and FS neurons. To assess the contribution of different glutamatergic receptors to the TC EPSCs recorded from Pyr and FS neurons, we sequentially and additively applied blockers for AMPA and NMDA receptors (20 $\mu \mathrm{M}$ DNQX and 50 $\mu \mathrm{M}$ APV). For these experiments, the TC terminal fields were stimulated using minimal light intensity to limit the contribution of the recurrent circuit to the evoked response. Neurons were recorded at $-70 \mathrm{mV}$ to isolate the component of the TC EPSC driven by AMPARs, and at $+40 \mathrm{mV}$ to isolate the NMDAR component. After acquisition of a $10 \mathrm{~min}$ baseline in regular ACSF, 20 $\mu \mathrm{M}$ DNQX was bath applied for 10-15 min. After that, a mix of $20 \mu \mathrm{M}$ DNQX and $50 \mu \mathrm{M}$ APV was perfused. The AMPAR- and NMDAR-mediated currents were then isolated and analyzed fol- 
lowing off-line subtraction (Fig. 5A,B). TC EPSCs in Pyr neurons comprised both an NMDAR- and an AMPAR-mediated component (Fig. 5C; NMDAR-mediated component, $54.9 \pm 10.3 \mathrm{pA}$; AMPARmediated component, $244.2 \pm 45.7 \mathrm{pA}$; $n=10)$. The NMDAR component accounted for about one third of the TC EPSC (Fig. 5D; NMDA/AMPA ratio: $0.27 \pm 0.06, n=10)$. The AMPARmediated current showed no rectification at $+40 \mathrm{mV}$, indicating that TC EPSCs in L4 Pyr neurons contain the AMPAR subunit GluA2 (Boulter et al., 1990; Verdoorn et al., 1991; Jonas and Burnashev, 1995). Differently, bath application of 20 $\mu \mathrm{M}$ DNQX completely blocked the TC EPSC in FS neurons, indicating that NMDARs did not contribute to the TC EPSCs in FS neurons (Fig. 5C; AMPARs: $554.6 \pm 90.7 \mathrm{pA}, n=5)$. No AMPAR- and NMDAR-dependent components were detected at $+40 \mathrm{mV}$, indicating that TC EPSCs in FS neurons are mediated by $\mathrm{Ca}^{2+}$ permeable GluA2-lacking AMPARs (Bowie and Mayer, 1995; Geiger et al., 1995) and lack NMDARs (Fig. 5D; NMDA/AMPA ratio for FS neurons $=0$ ). All FS neurons were recorded simultaneously with Pyr neurons, thus the differences observed cannot be ascribed to possible inconsistencies in the experimental preparation.

We further analyzed TC EPSCs to identify possible additional mechanisms contributing to the differences in the AMPAR-mediated component of TC EPSCs in Pyr and FS neurons. We used peak-scaled nonstationary noise analysis of TC EPSCs recorded at $-70 \mathrm{mV}$ in the presence of $50 \mu \mathrm{M}$ APV and evoked by minimal light intensity $\left(0.1 \mathrm{~mW} / \mathrm{mm}^{2}\right)$ to assess possible differences in single-channel conductance and the number of open channels contributing to the AMPA current of the TC EPSC (Sigworth, 1980; Traynelis and Jaramillo, 1998; Hartveit and Veruki, 2007). The peaks of 10 evoked TC EPSCs were scaled to the average peak amplitude (Fig. $6 A, B$ ), and the variance $\left(\sigma^{2}\right)$ during the decay phase was measured and plotted against the average amplitude (Fig. 6C,D). The plots were fitted with a parabolic curve (Fig. $6 C, D$, equation inset), and values for $i_{u}$ and $N_{o}$ were estimated from the equation. This analysis showed that TC EPSCs in Pyr neurons were mediated by a large number of open channels passing a small unitary current (Fig. 6E; Pyr neurons: $N_{o}, 101.9 \pm 21.9 ; i_{u}, 4.01 \pm 1.48 \mathrm{pA} ; n=11$ ); differently, TC EPSCs in FS neurons were mediated by a small number of open channels with large unitary current (Fig. $6 E$; FS neurons: $N_{o}$, $22.7 \pm 3.6 ; i_{u}, 26.2 \pm 6.1 \mathrm{pA} ; n=6$ ). Statistical comparisons of the number of open channels and unitary currents between cell types indicated significant differences (unpaired $t$ test: $N_{o}, p<0.02 ; i_{u}$, $p<0.02$ ). Together, these data demonstrate that differences in receptor composition, number of open channels, and singlechannel conductance explain part of the cell type-specific properties of TC EPSCs in L4 of the V1.
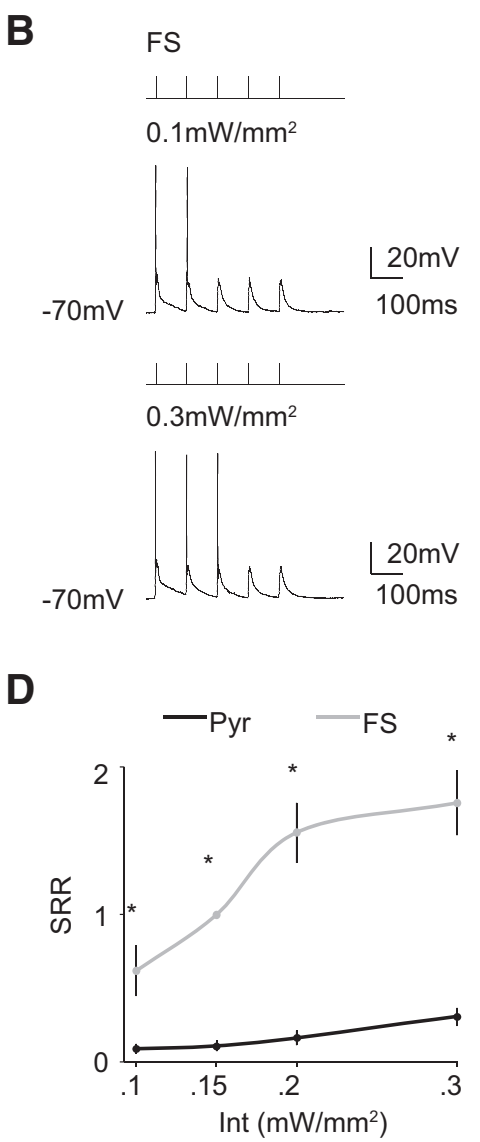

Figure 4. Feedforward inhibition prevents Pyr neurons from firing action potentials. $\boldsymbol{A}$, Top, TC EPSPs recorded from a Pyr gray). Bottom, TC EPSPs recorded from a Pyr neuron in response to light pulses with the highest stimulus intensity $\left(0.3 \mathrm{~mW} / \mathrm{mm}^{2}\right)$. $\boldsymbol{B}$, Top, TC EPSPs recorded from an FS neuron in current clamp at the lowest stimulus intensity $\left(0.1 \mathrm{~mW} / \mathrm{mm}^{2}\right)$. Bottom, TC EPSPS (from an FS neuron evoked using the highest stimulus intensity $\left(0.3 \mathrm{~mW} / \mathrm{mm}^{2}\right)$. C, Percentage of Pyr (black) and FS (gray) neurons that fired at least one action potential in response to light stimuli at the minimum $\left(0.1 \mathrm{~mW} / \mathrm{mm}^{2}\right)$ and maximum $\left(0.3 \mathrm{~mW} / \mathrm{mm}^{2}\right)$ light intensity. D, Spike reliability ratio, defined as the number of action potentials per light pulse, quantified for Pyr (black) and FS (gray) neurons as a function of the stimulus intensity. Data are presented as the mean \pm SE. Asterisks indicate significance.

\section{Cell type-specific presynaptic properties of LGN inputs in L4 of $\mathrm{V} 1$}

TC EPSCs in L4 of the V1 show cell type-specific short-term depression. This suggests that presynaptic mechanisms may also contribute to differentiate these inputs (O’Donovan and Rinzel, 1997; Stevens and Wesseling, 1998). To compare presynaptic properties, we recorded TC EPSCs in Pyr and FS neurons in the presence of $\mathrm{SrCl}_{2}(10 \mathrm{~mm}) . \mathrm{SrCl}_{2}$ desynchronizes release sites (Goda and Stevens, 1994; Bartley et al., 2008) and can be used to assess the number of release sites of a specific synapse (Gil et al., 1999; Daw et al., 2009; Hull et al., 2009). Following bath application of $\mathrm{SrCl}_{2}$, there was a significant reduction of TC EPSC amplitude in both Pyr and FS neurons (Fig. 7A-C; Pyr neurons: baseline, $408.5 \pm 62.2 \mathrm{pA} ; \mathrm{SrCl}_{2}, 332.2 \pm 47.7 \mathrm{pA}$; FS neurons: baseline, $675.8 \pm 102.9 \mathrm{pA} ; \mathrm{SrCl}_{2}, 505.03 \pm 89.05 \mathrm{pA}$; unpaired $t$ test, $p<0.04$; Pyr neurons, $n=17$; FS neurons, $n=6$ ). The magnitude of the decrease was significantly larger for TC EPSCs in FS neurons than in Pyr neurons (one-way ANOVA, $p<0.03$ ). $\mathrm{SrCl}_{2}$ application did not affect response latency (Pyr neurons: baseline, $2.54 \pm 0.09 \mathrm{~ms} ; \mathrm{SrCl}_{2}, 2.65 \pm 0.09 \mathrm{~ms}$; unpaired $t$ test, $p=0.5$; FS neurons: baseline, $1.93 \pm 0.17 \mathrm{~ms} ; \mathrm{SrCl}_{2}, 2.16 \pm 0.07$ $\mathrm{ms} ; p=0.12$ ) or rise time (Pyr neurons: baseline, $1.9 \pm 0.12 \mathrm{~ms}$; $\mathrm{SrCl}_{2}, 2.1 \pm 0.15 \mathrm{~ms} ; p=0.2$; FS neurons: baseline, $0.96 \pm 0.16$ 
A

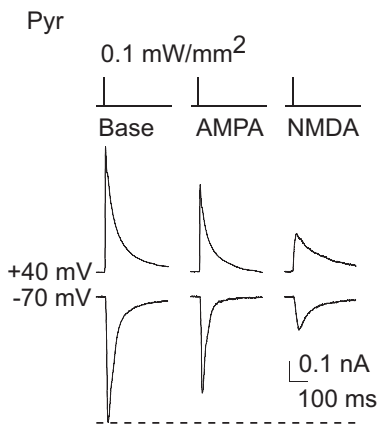

C

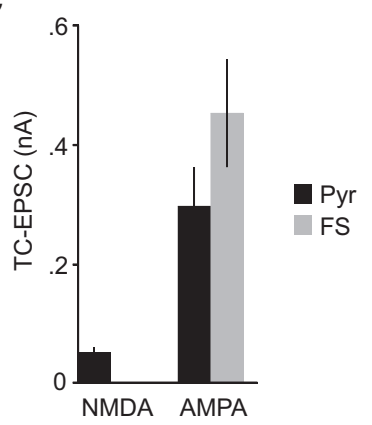

FS

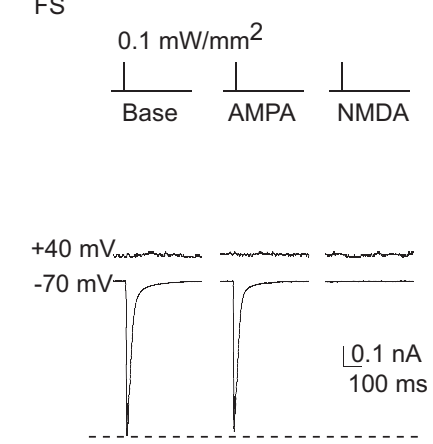

D

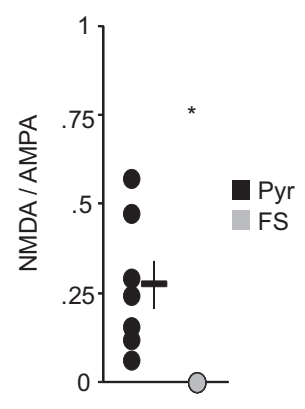

Figure 5. Different postsynaptic receptor contributions to TC EPSCs in Pyr and FS neurons. $A$, TC EPSCS (light intensity, $0.1 \mathrm{~mW} / \mathrm{mm}^{2}$ ) recorded at $-70 \mathrm{mV}$ and $+40 \mathrm{mV}$ to isolate baseline (left), AMPAR-mediated (middle), and NMDAR-mediated (right) currents in a Pyr neuron. B, TC EPSCS (light intensity, $0.1 \mathrm{~mW} / \mathrm{mm}^{2}$ ) recorded at $-70 \mathrm{mV}$ and $+40 \mathrm{mV}$ to isolate baseline (left), AMPAR-mediated (middle), and NMDAR-mediated (right) currents in an FS neuron. $C$, Average amplitude of NMDAR- and AMPAR-mediated currents from Pyr (black) and FS (gray) neurons. Data are presented as the mean \pm SE. D, NMDA/AMPA current ratio for Pyr (black) and FS (gray) neurons. Circles show individual ratios; the black bar shows the mean \pm SE. Asterisks indicate significant differences.

ms; $\mathrm{SrCl}_{2}, 1.03 \pm 0.17$; unpaired $t$ test, $\left.p=0.23\right)$. Application of $\mathrm{SrCl}_{2}$ also led to prolonged TC EPSCs, with multiple events becoming detectable during the decay phase. When the distribution of the number of events on the tail of TC EPSCs was quantified and compared between Pyr and FS neurons, we observed that a significantly larger number of events was detectable in FS neurons (Fig. $7 D$ ). The larger amplitude decrease and number of events following $\mathrm{SrCl}_{2}$ application strongly suggest that $\mathrm{TC}$ EPSCs in FS neurons depend on the activation of a larger number of release sites compared with those activated in Pyr neurons.

To further understand the presynaptic mechanisms that differentiate LGN inputs in L4 Pyr and FS neurons, we compared the CV of TC EPSCs before and after bath application of $\mathrm{SrCl}_{2}$. The baseline CV of TC EPSCs in both Pyr and FS neurons was already quite low, suggesting that LGN inputs in both neuron types have a high release probability. However, the CV of TC EPSCs in FS neurons was significantly lower than that in $\mathrm{Pyr}$ neurons (Fig. 7E; baseline CV: Pyr neurons, $0.12 \pm 0.01$; FS neurons, $0.07 \pm 0.01$; unpaired $t$ test, $p<0.006$; Pyr neurons, $n=17$; FS neurons, $n=6$ ). This indicates that LGN inputs in FS neurons likely have a higher release probability than those in Pyr neurons in response to a single stimulus. After $\mathrm{SrCl}_{2}$ application, the CV of TC EPSCs in Pyr neurons decreased significantly (Fig. $7 E, \mathrm{SrCl}_{2}$; Pyr neurons, $0.07 \pm 0.01$; paired $t$ test vs baseline CV, $p<0.01$ ), suggesting that TC EPSCs in Pyr neurons are mediated by the activation of a small number of inputs composed of a few, highly reliable release sites (Freund et al., 1985; Stratford et al., 1996).

Although the amplitude of TC ESPCs in FS neurons was significantly reduced by $\mathrm{SrCl}_{2}$, their $\mathrm{CV}$ remained unaltered (Fig. $7 E$, $\mathrm{SrCl}_{2}$; FS neurons, $0.067 \pm 0.005$ ), suggesting that this input is mediated by clusters of highly reliable release sites (Bagnall et al., 2011).

Quantal analysis of TC EPSCs before and after $\mathrm{SrCl}_{2}$ application was performed to further determine what mechanisms could account for the decrease in amplitude observed in TC EPSCs in FS neurons: release probability $(p)$, quantal size $(q)$, or number of release sites ( $n$; Sola et al., 2004). As shown in Figure $7 F$, all of the data point to TC EPSCs in FS neurons falling on or close to the unity line, suggesting that $\mathrm{SrCl}_{2}$ application affected the number of release sites at the LGN-FS synapse the most. As for Pyr neurons, the single data points were more scattered, although their average value was also positioned on the unity line. This suggests that $\mathrm{SrCl}_{2}$ application at the LGN-Pyr neuron synapse affects the number of release sites simultaneously activated by the light stimulus, but that additional effects of $\mathrm{SrCl}_{2}$ on release probability may also be involved.

Spearman rank order correlation analysis was used to determine whether the magnitude of the effect of $\mathrm{SrCl}_{2}$ was correlated with the baseline amplitude of TC EPSCs. Pyr neurons showed no significant correlation $(R=0.39, p=0.11)$, consistent with the small effect or lack of effect of $\mathrm{SrCl}_{2}$ on the amplitude of TC EPSC on most Pyr neurons (14 of 17 neurons) recorded (Fig. 7G; $R=$ $0.15 ; n=17)$. Differently, FS neurons showed a significant correlation between the initial TC EPSC amplitude and the magnitude of the effect of $\mathrm{SrCl}_{2}$ (Fig. $7 H ; R=0.83 ; p<0.05 ; n=6$ ). These results support the interpretation that the amplitude of the TC EPSC in FS neurons depends on the number of release sites located at the LGN terminals in FS synapse. All FS neurons were recorded simultaneously with pyramidal neurons, and only the lowest stimulus intensity was used for these experiments $(0.1$ $\mathrm{mW} / \mathrm{mm}^{2}$ ) to minimize the contribution of recurrent intracortical circuits. Our results indicate that LGN inputs in Pyr and FS neurons rely on target-specific presynaptic and postsynaptic mechanisms. Thus, differences in LGN activation of Pyr and FS neurons may account, at least in part, for their distinct functional properties.

\section{Discussion}

We have analyzed the properties of LGN synapses in Pyr and FS neurons in L4 in the V1. LGN inputs in Pyr and FS neurons presented some similarities - they were powerful and reliable, and showed short-term depression in response to repetitive stimulation-but relied on distinct presynaptic and postsynaptic mechanisms. A larger proportion of FS neurons reliably fired action potentials at all stimulation intensities, indicating that single incoming stimuli likely activate feedforward inhibitory circuitry more effectively than excitatory circuits. This is consistent with previous findings showing that in vivo putative inhibitory neurons show higher activity evoked by visual stimuli than excitatory neurons (Zhuang et al., 2013). TC EPSCs in FS neurons were larger and depressed more in response to repetitive stimulation than TC EPSCs in Pyr neurons, suggesting that stimuli containing trains of spikes could successfully overcome feedforward inhibition and drive excitatory neurons.

TC EPSCs in Pyr and FS neurons showed target-specific presynaptic and postsynaptic properties. LGN synapses in Pyr neurons activated both NMDARs and AMPARs. The AMPARmediated current had similar amplitudes at positive and negative potentials, indicating a contribution of calcium-impermeable AMPARs (Boulter et al., 1990; Verdoorn et al., 1991; Jonas and 
Burnashev, 1995). The NMDAR-mediated current was large at $-70 \mathrm{mV}$, suggesting that these receptors contain $\mathrm{Mg}^{2+}$-insensitive subunits and contribute to evoked responses at resting membrane potential (Fleidervish et al., 1998; Binshtok et al., 2006). LGN synapses in FS neurons lacked NMDAR-mediated currents and contained inwardly rectifying AMPARmediated currents, indicating that these receptors lack the GluA2 subunit and are likely calcium permeable (Bowie and Mayer, 1995; Geiger et al., 1995). Peakscaled nonstationary noise analysis of the AMPAR-mediated current showed that TC EPSCs in Pyr neurons resulted from the activation of many open channels with small unitary current, consistent with the presence of GluA2-containing AMPA receptors (Swanson et al., 1997). Differently, TC EPSCs in FS neurons depend on a small number of open channels with large unitary current, consistent with the presence of GluA2-lacking AMPARs (Hestrin, 1993).

The differences in short-term dynamics and the effects of strontium chloride on TC EPSCs indicate that LGN inputs also have target-specific presynaptic properties. Strontium chloride induced small, although significant, changes in the amplitude of TC EPCS in Pyr neurons. Few quantal events were detected after the first evoked response, suggesting that LGN synapses in Pyr neurons contain a small number of powerful release sites. This is consistent with the shallow slope of the input-output curve for TC EPSCs in Pyr neurons, their low coefficient of variation, and with previous reports that single LGN axons make a small number of synaptic contacts with L4 excitatory neurons in the V1 (Freund et al., 1985; Peters and Payne, 1993; da Costa and Martin, 2009). The amplitude of TC EPSCs in FS neurons was reduced by one third to one half by the application of strontium chloride. Up to 20 quantal events could be detected in the window following the onset of the light stimulus. The magnitude of the effect of strontium strongly correlated with baseline TC EPSC amplitude, suggesting that at LGN-FS synapses the largest the TC EPSC, the higher the number of release sites activated by a stimulus. Combined with lack of changes in CV following strontium chloride, these results suggest that LGN-FS synapses contain clusters of release sites that account for one third to one half of the amplitude of a TC EPSC (Bagnall et al., 2011). This interpretation fits well with the observation that the input-output curve of TC EPSCs in FS neurons has a steeper slope than that for Pyr neurons.

Our results demonstrate that LGN afferents engage targetspecific presynaptic and postsynaptic mechanisms to activate feedforward excitatory and inhibitory circuits in L4 of the V1. LGN inputs in principle carry the same information. Targetspecific synaptic properties may contribute at least in part to explaining why Pyr and FS neurons present distinct responsiveness to incoming stimuli (Bruno and Simons, 2002; Contreras and Palmer, 2003; Swadlow, 2002, 2003; Alonso and Swadlow,
B FS

E

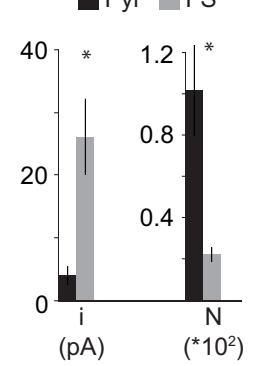

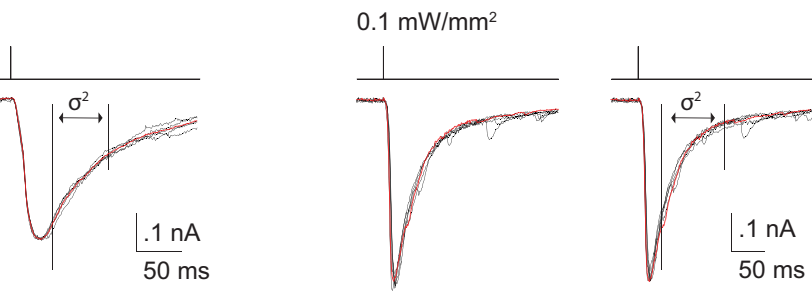

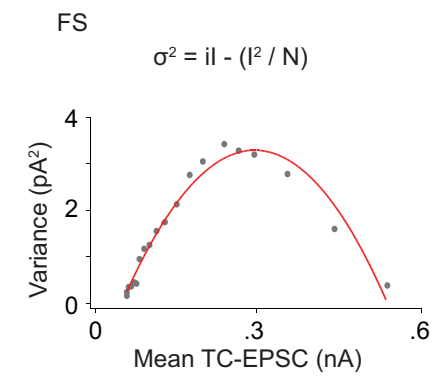

D

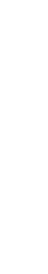

Figure 6. Cell type-specific single-channel conductance and the number of open channels at LGN synapses in Pyr and FS neurons. $A$, Raw traces of TC EPSCs recorded from one Pyr neuron (black) overlayed by their average TC EPSC (red). The left pane she of variation around the mean amplitude, while, the right panel shows the peak-scaled variation around the (right, gray dots), and fitted with a parabolic curve (red). The curve equation is shown above the graphs. The fit was used to estimate values for $i_{u}$ and $N_{o}$. E, Bar graph comparing $i_{u}$ and $N_{o}$ for Pyr (black) and FS (gray) neurons. Data are presented as the mean $\pm S E$. Asterisks indicate significant differences.

2005; Cardin et al., 2007). FS neurons have lower input resistance and higher spike thresholds than Pyr neurons, but the large amplitude of the TC EPSCs they receive is quite effective at driving them above threshold. This is likely due to the organization of LGN inputs on FS neurons, which, according to our analysis, is consistent with the presence of clusters of release sites (Bagnall et al., 2011) with high release probability that activate few postsynaptic channels with large conductance. It is also consistent with the finding that FS neurons receive powerful direct inputs from retinotopically aligned LGN neurons (Zhuang et al., 2013). The powerful short-term depression, fast rise, and decay kinetics, and lack of NMDARs at LGN-FS synapses are likely contributing to evoking fast and precisely timed responses to visual stimuli. These properties likely narrow the temporal window of activation of these neurons (Jonas et al., 2004; Cardin et al., 2010). In our experiments, FS neurons were driven above threshold even by relatively weak light pulses. The large evoked TC EPSCs are consistent with previous reports that inhibitory neurons directly driven by the LGN respond more strongly than excitatory neurons to visual stimuli (Zhuang et al., 2013). Differently, LGN-Pyr neuron synapses rely on few powerful release sites that activate a large number of channels with small conductance. The effects of moderate short-term depression of these inputs, the presence of NMDARs on postsynaptic terminals, and the control of feedforward inhibition on their ability to fire action potentials may explain the favoring of Pyr neurons narrower tuning to visual stimuli. The target-specific properties of TC inputs in FS and Pyr neurons may provide a synaptic mechanism to explain the 
A

Pyr

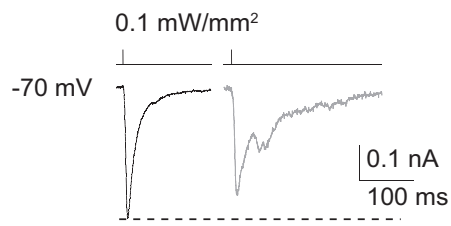

Baseline $\quad \mathrm{SrCl}_{2}$

C

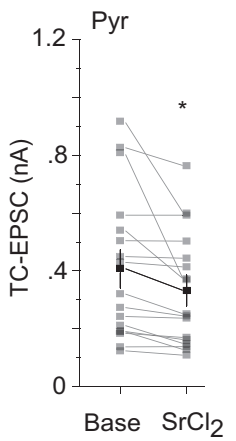

E

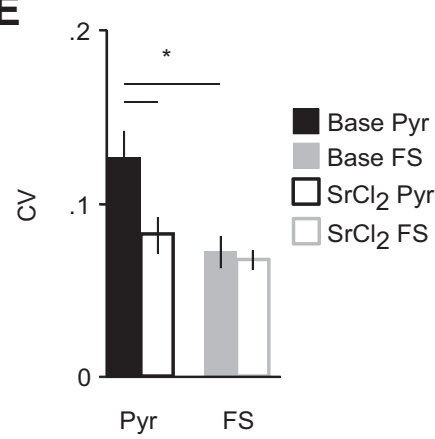

G

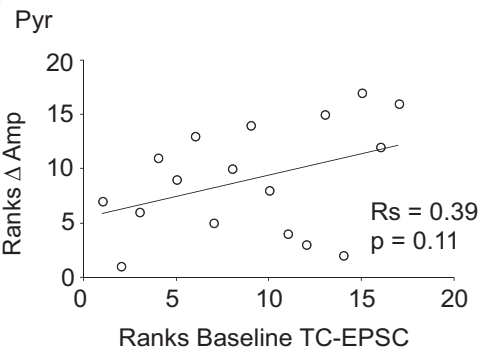

B

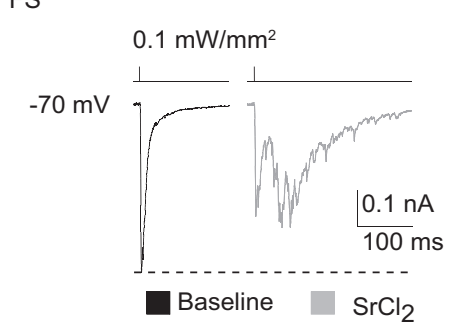

D

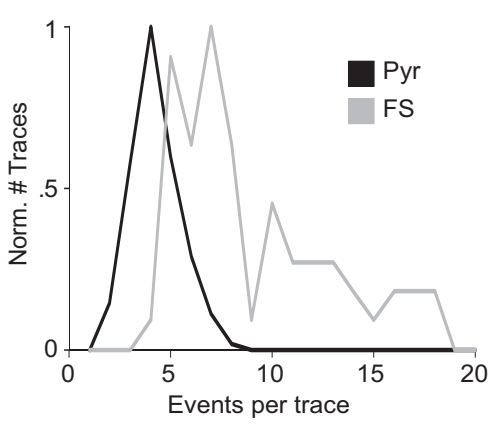

$\mathbf{F}$

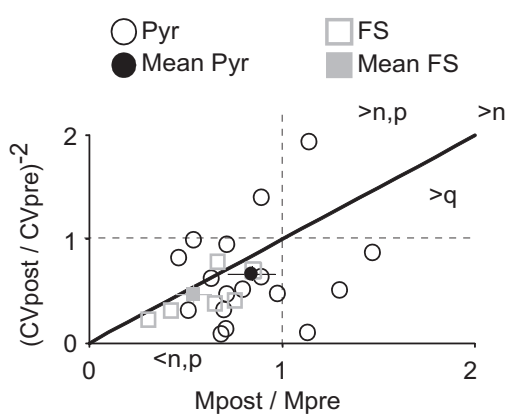

H

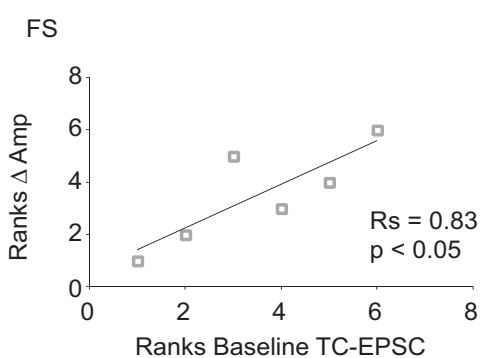

Figure 7. Physiological evidence for target-specific presynaptic properties at LGN-V1 inputs. $\boldsymbol{A}$, Left, Average TC EPSC recorded from one Pyr neuron before (baseline; black) application of $\mathrm{SrCl}_{2}$. Right, Single evoked TC EPSC recorded from the same Pyr neuron in the presence of $10 \mathrm{~mm} \mathrm{SrCl}_{2} / 0 \mathrm{~mm} \mathrm{CaCl}$ (gray). Light stimulus, $0.1 \mathrm{~mW} / \mathrm{mm}^{2}$. $\boldsymbol{B}$, Left, Average TC EPSC (black) recorded from one $\mathrm{FS}$ neuron before the perfusion of $\mathrm{SrCl}_{2}$. Right, Single evoked TC EPSC recorded from the same FS neuron in the presence of $10 \mathrm{~mm} \mathrm{SrCl} / 2 \mathrm{~mm} \mathrm{CaCl}$ (gray). Light stimulus, $0.1 \mathrm{~mW} / \mathrm{mm}^{2}$. C, Effect of strontium on the amplitude of TC EPSCs for Pyr (left; dark gray) and FS (right; light gray) neurons; the average effect for both neuron types is shown in black in both plots. The dark gray and light gray markers indicate single recordings for Pyr and FS neurons, respectively. $\boldsymbol{D}$, Distribution of the number of events in the $200 \mathrm{~ms}$ time window following the onset of the stimulus (the first evoked TC EPSC is excluded from the count). Black, Pyr; gray, FS; bin size, one event. $\boldsymbol{E}$, CV of the amplitude of the first evoked TC EPSC before (filled bars) and after (open bars) application of $\mathrm{SrCl}_{2} / 0 \mathrm{~mm} \mathrm{CaCl}$ for Pyr (black) and FS (gray) neurons. Data are presented as the mean \pm SE. Asterisks indicate significant difference. $\boldsymbol{F}$, Graphic representation of quantal analysis of TC EPSC amplitudes. Black open circles, Data from each Pyr neuron; black filled circle, Pyr average; gray open squares, data from each FS neuron; filled gray square, $\mathrm{FS}$ average; CV pre, baseline CV; CV post, $\mathrm{CV}_{\text {after }} \mathrm{SrCl}_{2} / 0 \mathrm{~mm}$ $\mathrm{CaCl}_{2} ;$ Mpre, mean baseline TC EPSC amplitude; Mpost, mean TC EPSC after $\mathrm{SrCl}_{2} / 0 \mathrm{~mm} \mathrm{CaCl} ; n$, number of release sites; $p$, release probability; q, quantal size; solid line, unity line. Average data are presented as the mean \pm SE. G, Spearman rank order correlation of baseline TC EPSC amplitude in a Pyr neuron versus the change in TC EPSC amplitude in $\mathrm{SrCl}_{2} / 0 \mathrm{~mm} \mathrm{CaCl}_{2}$. $\boldsymbol{H}$, Spearman rank order correlation of the baseline TC EPSC amplitude in FS neurons versus the change in TC EPSC amplitude in $\mathrm{SrCl}_{2} / 0 \mathrm{~mm} \mathrm{CaCl}$. For $\mathbf{G}$ and $\boldsymbol{H}$ : Rs, Spearman coefficients; $p$ values $<0.05$ indicate significant correlations.

broader tuning of FS neurons for stimulus orientation, direction, and spatial and temporal frequency of visual stimuli observed in vivo (Zhuang et al., 2013).

Coactivation of feedforward excitatory and inhibitory neurons by TC afferents is thought to be critical for regulating the precision of cortical neuron activation and cortical excitability. The properties of LGN-FS neuron inputs suggest that this feedforward inhibitory circuit provide a "window of excitability" (Swadlow, 2002, 2003; Wilent and Contreras, 2004) that ensures temporal precision of the transformation of synaptic inputs into neuronal firing rates (Wehr and Zador, 2003; Gabernet et al., 2005; Priebe and Ferster, 2005). The high spike reliability ratio of FS neurons in response to LGN terminal field activation supports the interpretation that LGN inputs successfully drive pyramidal neurons above threshold in a narrow window preceding the arrival of the inhibitory signal from FS neurons.

LGN-FS neuron synapses may also regulate circuit excitability by preventing runaway excitation (Swadlow, 2003; Sun et al., 2006). Indeed, the blockade of inhibition increased the ability of L4 Pyr neurons to fire action potentials. Finally, the activation of synapses containing NMDARs versus $\mathrm{Ca}^{2+}$-permeable AMPARs provides a differential mode of regulation of intracellular calcium dynamics (Geiger et al., 1995; Dingledine et al., 1999), which can drive distinct signaling mechanisms in synaptic plasticity (Isaac et al., 2007; Gainey et al., 2009). As a consequence, the different mechanisms of activation of LGN inputs in Pyr and FS neurons may provide a substrate for connection-specific plasticity in L4 of the V1.

When our results are compared with findings from other sensory areas, it becomes evident that LGN inputs in L4 of the V1 present some similarities, but also significant differences. In S1 and A1, TC inputs in excitatory neurons activate AMPARs and NMDARs in postsynaptic terminals (Cruikshank et al., 2002; Rose and Metherate, 2005; Hull et al., 2009; Schiff and Reyes, 2012). The AMPARmediated components in excitatory neurons have properties similar to those we reported in V1. In S1 and V1, the NMDAR-mediated component of the TC EPSC can be detected at negative potentials, and these TC inputs activate NMDARs with low sensitivity to block $\mathrm{Mg}^{2+}$ (Fleidervish et al., 1998; Binshtok et al., 2006; Hull et al., 2009).

Similar to $\mathrm{S} 1$ and A1, the stimulation of LGN inputs in FS neurons evokes TC 
EPSCs that have larger amplitudes than those in excitatory neurons (Hull et al., 2009; Cruikshank et al., 2007, 2010; Schiff and Reyes, 2012). TC inputs in FS neurons are mediated by GluRA2lacking AMPA receptors in both S1 and V1. No NMDARmediated current contributed to TC EPSCs in FS neurons in V1; whereas in S1 and A1 TC EPSCs in FS neurons contain NMDARmediated currents, albeit smaller than those recorded from excitatory neurons (Hull et al., 2009). The data from V1 are consistent with observations in the prefrontal cortex, where TC EPSCs in $78 \%$ of FS neurons were mediated by GluR2-lacking AMPARs and lacked NMDAR-mediated currents (Wang and Gao, 2010). Differences in short-term depression were observed at TC inputs in excitatory neurons and FS neurons in S1 (Beierlein et al., 2003; but see Hull et al., 2009; Cruikshank et al., 2010; Viaene et al., 2011), A1 (Lee and Sherman, 2008; Schiff and Reyes, 2012), and V1 (this study), suggesting that distinct short-term dynamics are a general property of TC circuits, although the mechanisms engaged may differ across areas (Hull et al., 2009).

The organization of TC inputs also shows similarities and significant differences across sensory cortices. Our results suggest that LGN inputs in L4 of the V1 are mediated by a few powerful release sites, or clusters of release sites in the case of FS neurons, which is consistent with anatomical studies (Freund et al., 1985; Stratford et al., 1996; Ahmed et al., 1997; Erisir and Dreusicke, 2005). TC inputs are outnumbered by intracortical inputs (Peters and Payne, 1993; Ahmed et al., 1994, 1997; da Costa and Martin, 2009); however, feedforward stimuli are effectively propagated in cortical circuits. It was proposed that the amplification of signals by intracortical synapses may be necessary to propagate incoming activity in V1 and A1 (da Costa and Martin, 2011; Schiff and Reyes, 2012; Lee, 2013; Li et al., 2013). This presents significant differences with models of S1 activation. In S1, TC inputs in excitatory neurons have a quantal size similar to those of intracortical inputs (Gil et al., 1999; Schoonover et al., 2014). S1 activation by TC afferents is thought to depend on synchronous activation of numerous weak synapses (Bruno and Sakmann, 2006) with three times the number of release sites of intracortical synapses and a higher release probability (Hull et al., 2009; Schoonover et al., 2014). The similarities reported across sensory cortices likely underlie a set of general principles of TC circuit organization. The differences suggest that region-specific properties of TC inputs may depend on the specific demands of distinct sensory modalities.

\section{References}

Agmon A, Connors BW (1992) Correlation between intrinsic firing patterns and thalamocortical synaptic responses of neurons in mouse barrel cortex. J Neurosci 12:319-329. Medline

Ahmed B, Anderson JC, Douglas RJ, Martin KA, Nelson JC (1994) Polyneuronal innervation of spiny stellate neurons in cat visual cortex. J Comp Neurol 341:39-49. CrossRef Medline

Ahmed B, Anderson JC, Martin KA, Nelson JC (1997) Map of the synapses onto layer 4 basket cells of the primary visual cortex of the cat. J Comp Neurol 380:230-242. CrossRef Medline

Alonso JM, Swadlow HA (2005) Thalamocortical specificity and the synthesis of sensory cortical receptive fields. J Neurophysiol 94:26-32. CrossRef Medline

Atallah BV, Bruns W, Carandini M, Scanziani M (2012) Parvalbuminexpressing interneurons linearly transform cortical responses to visual stimuli. Neuron 73:159-170. CrossRef Medline

Bagnall MW, Hull C, Bushong EA, Ellisman MH, Scanziani M (2011) Multiple clusters of release sites formed by individual thalamic afferents onto cortical interneurons ensure reliable transmission. Neuron 71:180-194. CrossRef Medline

Bartley AF, Huang ZJ, Huber KM, Gibson JR (2008) Differential activity- dependent, homeostatic plasticity of two neocortical inhibitory circuits. J Neurophysiol 100:1983-1994. CrossRef Medline

Beierlein M, Gibson JR, Connors BW (2003) Two dynamically distinct inhibitory networks in layer 4 of the neocortex. J Neurophysiol 90:29873000. CrossRef Medline

Binshtok AM, Fleidervish IA, Sprengel R, Gutnick MJ (2006) NMDA receptors in layer 4 spiny stellate cells of the mouse barrel cortex contain the NR2C subunit. J Neurosci 26:708-715. CrossRef Medline

Boulter J, Hollmann M, O'Shea-Greenfield A, Hartley M, Deneris E, Maron C, Heinemann S (1990) Molecular cloning and functional expression of glutamate receptor subunit genes. Science 249:1033-1037. CrossRef Medline

Bowie D, Mayer ML (1995) Inward rectification of both AMPA and kainate subtype glutamate receptors generated by polyamine-mediated ion channel block. Neuron 15:453-462. CrossRef Medline

Bruno RM, Sakmann B (2006) Cortex is driven by weak but synchronously active thalamocortical synapses. Science 312:1622-1627. CrossRef Medline

Bruno RM, Simons DJ (2002) Feedforward mechanisms of excitatory and inhibitory cortical receptive fields. J Neurosci 22:10966-10975. Medline

Cardin JA, Palmer LA, Contreras D (2007) Stimulus feature selectivity in excitatory and inhibitory neurons in primary visual cortex. J Neurosci 27:10333-10344. CrossRef Medline

Cardin JA, Kumbhani RD, Contreras D, Palmer LA (2010) Cellular mechanisms of temporal sensitivity in visual cortex neurons. J Neurosci 30: 3652-3662. CrossRef Medline

Contreras D, Palmer L (2003) Response to contrast of electrophysiologically defined cell classes in primary visual cortex. J Neurosci 23:6936-6945. Medline

Cottam JC, Smith SL, Häusser M (2013) Target-specific effects of somatostatin-expressing interneurons on neocortical visual processing. J Neurosci 33:19567-19578. CrossRef Medline

Cruikshank SJ, Rose HJ, Metherate R (2002) Auditory thalamocortical synaptic transmission in vitro. J Neurophysiol 87:361-384. Medline

Cruikshank SJ, Lewis TJ, Connors BW (2007) Synaptic basis for intense thalamocortical activation of feedforward inhibitory cells in neocortex. Nat Neurosci 10:462-468. CrossRef Medline

Cruikshank SJ, Urabe H, Nurmikko AV, Connors BW (2010) Pathway-specific feedforward circuits between thalamus and neocortex revealed by selective optical stimulation of axons. Neuron 65:230-245. CrossRef Medline

da Costa NM, Martin KA (2009) The proportion of synapses formed by the axons of the lateral geniculate nucleus in layer 4 of area 17 of the cat. J Comp Neurol 516:264-276. CrossRef Medline

da Costa NM, Martin KA (2011) How thalamus connects to spiny stellate cells in the cat's visual cortex. J Neurosci 31:2925-2937. CrossRef Medline

Daw MI, Tricoire L, Erdelyi F, Szabo G, McBain CJ (2009) Asynchronous transmitter release from cholecystokinin-containing inhibitory interneurons is widespread and target-cell independent. J Neurosci 29:1111211122. CrossRef Medline

Dingledine R, Borges K, Bowie D, Traynelis SF (1999) The glutamate receptor ion channels. Pharmacol Rev 51:7-61. Medline

Erisir A, Dreusicke M (2005) Quantitative morphology and postsynaptic targets of thalamocortical axons in critical period and adult ferret visual cortex. J Comp Neurol 485:11-31. CrossRef Medline

Fleidervish IA, Binshtok AM, Gutnick MJ (1998) Functionally distinct NMDA receptors mediate horizontal connectivity within layer 4 of mouse barrel cortex. Neuron 21:1055-1065. CrossRef Medline

Freund TF, Martin KA, Somogyi P, Whitteridge D (1985) Innervation of cat visual areas 17 and 18 by physiologically identified X-and Y-type thalamic afferents. II. Identification of postsynaptic targets by GABA immunocytochemistry and Golgi impregnation. J Comp Neurol 242:275-291. CrossRef Medline

Gabernet L, Jadhav SP, Feldman DE, Carandini M, Scanziani M (2005) Somatosensory integration controlled by dynamic thalamocortical feedforward inhibition. Neuron 48:315-327. CrossRef Medline

Gainey MA, Hurvitz-Wolff JR, Lambo ME, Turrigiano GG (2009) Synaptic scaling requires the GluR2 subunit of the AMPA receptor. J Neusci 29: 6479-6489. CrossRef Medline

Geiger JR, Melcher T, Koh DS, Sakmann B, Seeburg PH, Jonas P, Monyer H (1995) Relative abundance of subunit mRNAs determines gating and $\mathrm{Ca} 2+$ permeability of AMPA receptors in principal neurons and interneurons in rat CNS. Neuron 15:193-204. CrossRef Medline

Gil Z, Connors BW, Amitai Y (1999) Efficacy of thalamocortical and intracortical synaptic connections: quanta, innervation, and reliability. Neuron 23:385-397. CrossRef Medline 
Goda Y, Stevens CF (1994) Two components of transmitter release at a central synapse. Proc Natl Acad Sci U S A 91:12942-12946. CrossRef Medline

Gu Y, Arruda-Carvalho M, Wang J, Janoschka SR, Josselyn SA, Frankland PW, Ge S (2012) Optical controlling reveals time-dependent roles for adultborn dentate granule cells. Nat Neurosci 15:1700-1706. CrossRef Medline

Hartveit E, Veruki ML (2007) Studying properties of neurotransmitter receptors by non-stationary noise analysis of spontaneous postsynaptic currents and agonist-evoked responses in outside-out patches. Nat Protoc 2:434-448. CrossRef Medline

Hestrin S (1993) Different glutamate receptor channels mediate fast excitatory synaptic currents in inhibitory and excitatory cortical neurons. Neuron 11:1083-1091. CrossRef Medline

Hull C, Isaacson JS, Scanziani M (2009) Postsynaptic mechanisms govern the differential excitation of cortical neurons by thalamic inputs. J Neurosci 29:9127-9136. CrossRef Medline

Isaac JT, Ashby MC, McBain CJ (2007) The role of the GluR2 subunit in AMPA receptor function and synaptic plasticity. Neuron 54:859-871. CrossRef Medline

Jonas P, Burnashev N (1995) Molecular mechanisms controlling calcium entry through AMPA-type glutamate receptor channels. Neuron 15:987990. CrossRef Medline

Jonas P, Bischofberger J, Fricker D, Miles R (2004) Interneuron Diversity series: fast in, fast out-temporal and spatial signal processing in hippocampal interneurons. Trends Neurosci 27:30-40. CrossRef Medline

Kameyama K, Sohya K, Ebina T, Fukuda A, Yanagawa Y, Tsumoto T (2010) Difference in binocularity and ocular dominance plasticity between GABAergic and excitatory cortical neurons. J Neurosci 30:1551-1559. CrossRef Medline

Kuhlman SJ, Tring E, Trachtenberg JT (2011) Fast-spiking interneurons have an initial orientation bias that is lost with vision. Nat Neurosci 14: 1121-1123. CrossRef Medline

Lee CC (2013) Thalamic and cortical pathways supporting auditory processing. Brain Lang 126:22-28. CrossRef Medline

Lee CC, Sherman SM (2008) Synaptic properties of thalamic and intracortical inputs to layer 4 of the first- and higher-order cortical areas in the auditory and somatosensory systems. J Neurophysiol 100:317-326. CrossRef Medline

Li LY, Li YT, Zhou M, Tao HW, Zhang LI (2013) Intracortical multiplication of thalamocortical signals in mouse auditory cortex. Nat Neurosci 16:1179-1181. CrossRef Medline

Li YT, Ma WP, Pan CJ, Zhang LI, Tao HW (2012) Broadening of cortical inhibition mediates developmental sharpening of orientation selectivity. J Neurosci 32:3981-3991. CrossRef Medline

MacLean JN, Fenstermaker V, Watson BO, Yuste R (2006) A visual thalamocortical slice. Nat Methods 3:129-134. CrossRef Medline

Morishita W, Alger BE (1997) Sr2+ supports depolarization-induced suppression of inhibition and provides new evidence for a presynaptic expression mechanism in rat hippocampal slices. J Physiol 505:307-317. CrossRef Medline

Niell CM, Stryker MP (2008) Highly selective receptive fields in mouse visual cortex. J Neurosci 28:7520-7536. CrossRef Medline

O’Donovan MJ, Rinzel J (1997) Synaptic depression: a dynamic regulator of synaptic communication with varied functional roles. Trends Neurosci 20:431-433. CrossRef Medline

Peters A, Payne BR (1993) Numerical relationships between geniculocortical afferents and pyramidal cell modules in cat primary visual cortex. Cereb Cortex 3:69-78. CrossRef Medline

Priebe NJ, Ferster D (2005) Direction selectivity of excitation and inhibition in simple cells of the cat primary visual cortex. Neuron 45:133-145. CrossRef Medline

Rose HJ, Metherate R (2005) Auditory thalamocortical transmission is reliable and temporally precise. J Neurophysiol 94:2019-2030. CrossRef Medline

Runyan CA, Sur M (2013) Response selectivity is correlated to dendritic structure in parvalbumin-expressing inhibitory neurons in visual cortex. J Neurosci 33:11724-11733. CrossRef Medline

Schiff ML, Reyes AD (2012) Characterization of thalamocortical responses of regular-spiking and fast-spiking neurons of the mouse auditory cortex in vitro and in silico. J Neurophysiol 107:1476-1488. CrossRef Medline

Schoonover CE, Tapia JC, Schilling VC, Wimmer V, Blazeski R, Zhang W, Mason CA, Bruno RM (2014) Comparative strength and dendritic or- ganization of thalamocortical and corticocortical synapses onto excitatory layer 4 neurons. J Neurosci 34:6746-6758. CrossRef Medline

Sherman SM (2007) The thalamus is more than just a relay. Curr Opin Neurobiol 17:417-422. CrossRef Medline

Sherman SM (2012) Thalamocortical interactions. Curr Opin Neurobiol 22:575-579. CrossRef Medline

Sigworth FJ (1980) The variance of sodium current fluctuations at the node of Ranvier. J Physiol 307:97-129. Medline

Sola E, Prestori F, Rossi P, Taglietti V, D’Angelo E (2004) Increased neurotransmitter release during long-term potentiation at mossy fiber-granule cell synapses in rat cerebellum. J Physiol 557:843-861. CrossRef Medline

Stevens CF, Wesseling JF (1998) Activity-dependent modulation of the rate at which synaptic vesicles become available to undergo exocytosis. Neuron 21:415-424. CrossRef Medline

Stratford KJ, Tarczy-Hornoch K, Martin KAC, Bannister NJ, Jack JJB (1996) Excitatory synaptic inputs to spiny stellate cells in cat visual cortex. Nature 382:258-261. CrossRef Medline

Sun QQ, Huguenard JR, Prince DA (2006) Barrel cortex microcircuits: thalamocortical feedforward inhibition in spiny stellate cells is mediated by a small number of fast-spiking interneurons. J Neurosci 26:1219-1230. CrossRef Medline

Swadlow HA (2002) Thalamocortical control of feed-forward inhibition in awake somatosensory "barrel" cortex. Philos Trans R Soc Lond B Biol Sci 357:1717-1727. CrossRef Medline

Swadlow HA (2003) Fast-spike interneurons and feedforward inhibition in awake sensory neocortex. Cereb Cortex 13:25-32. CrossRef Medline

Swanson GT, Kamboj SK, Cull-Candy SG (1997) Single-channel properties of recombinant AMPA receptors depend on RNA editing, splice variation, and subunit composition. J Neurosci 17:58-69. Medline

Traynelis SF, Jaramillo F (1998) Getting the most out of noise in the central nervous system. Trends Neurosci 21:137-145. CrossRef Medline

Verdoorn TA, Burnashev N, Monyer H, Seeburg PH, Sakmann B (1991) Structural determinants of ion flow through recombinant glutamate receptor channels. Science 252:1715-1718. CrossRef Medline

Viaene AN, Petrof I, Sherman SM (2011) Synaptic properties of thalamic input to the subgranular layers of primary somatosensory and auditory cortices in the mouse. J Neurosci 31:12738-12747. CrossRef Medline

Wang HX, Gao WJ (2010) Development of calcium-permeable AMPA receptors and their correlation with NMDA receptors in fast-spiking interneurons of rat prefrontal cortex. J Physiol 588:2823-2838. CrossRef Medline

Wang L, Fontanini A, Maffei A (2012) Experience-dependent switch in sign and mechanisms for plasticity in layer 4 of primary visual cortex. J Neurosci 32:10562-10573. CrossRef Medline

Wang L, Kloc M, Gu Y, Ge S, Maffei A (2013) Layer-specific experiencedependent rewiring of thalamocortical circuits. J Neurosci 33:4181-4191. CrossRef Medline

Wehr M, Zador AM (2003) Balanced inhibition underlies tuning and sharpens spike timing in auditory cortex. Nature 426:442-446. CrossRef Medline

Wernig A (1975) Estimates of statistical release parameters from crayfish and frog neuromuscular junction. J Physiol 244:207-221. Medline

Wilent WB, Contreras D (2004) Synaptic responses to whisker deflections in rat barrel cortex as a function of cortical layer and stimulus intensity. J Neurosci 24:3985-3998. CrossRef Medline

Xu-Friedman MA, Regehr WG (2000) Probing fundamental aspects of synaptic transmission with strontium. J Neurosci 20:4414-4422. Medline

Yazaki-Sugiyama Y, Kang S, Câteau H, Fukai T, Hensch TK (2009) Bidirectional plasticity in fast-spiking GABA circuits by visual experience. Nature 462:218-221. CrossRef Medline

Zariwala HA, Madisen L, Ahrens KF, Bernard A, Lein ES, Jones AR, Zeng H (2011) Visual tuning properties of genetically identified layer $2 / 3$ neuronal types in the primary visual cortex of cre-transgenic mice. Front Syst Neurosci 4:162. CrossRef Medline

Zhang F, Wang LP, Boyden ES, Deisseroth K (2006) Channelrhodopsin-2 and optical control of excitable cells. Nat Methods 3:785-792. CrossRef Medline

Zhuang J, Stoelzel CR, Bereshpolova Y, Huff JM, Hei X, Alonso JM, Swadlow HA (2013) Layer 4 in prmary visual cortex of the awake rabbit: contrasting properties of simple cells and putative feedforward inhibitory interneurons. J Neurosci 33:11372-11389. CrossRef Medline 